\title{
Vibration Analysis and Human Comfort Evaluation of Steel-Concrete Composite Footbridges Based on the Modelling of the Pedestrian- Structure Dynamic Interaction Effect
}

\author{
J.G. Santos da Silva*, R.B. Burgos*, I.F.B. Duarte**, G.L. Debona** \\ *(Structural Engineering Department. State University of Rio de Janeiro.Rio de Janeiro/RJ, Brazil) \\ **(Civil Engineering Post-graduate Programme. State University of Rio de Janeiro, Rio de Janeiro/RJ, Brazil)
}

\begin{abstract}
This work aims the development of an analysis methodology to investigate the dynamic behaviour of steelconcrete composite footbridges. The composite footbridge dynamic response is analysed based on two different strategies. Firstly, the traditional simulation of human walking, without consideration of the pedestrianfootbridge dynamic interaction effect is considered. On the other hand, the effect of the dynamics of the pedestrians while crossing footbridges in crowd situations is analysed and the pedestrian-footbridge dynamic interaction, based on the use of biodynamic models is investigated using a second strategy. The investigated structural system corresponds to an existing pedestrian footbridge built on Ayrton Senna Av. in the city of Rio de Janeiro/RJ, Brazil, with a central span of $68.6 \mathrm{~m}$. The footbridge dynamic response was obtained and compared to the limiting values proposed by several authors and design standards. The results indicate that the biodynamic loading models lead to peak accelerations values lower than those produced by the traditional methods. These results provided evidence that the pedestrian-structure dynamic interaction effect should be considered when composite footbridges are subjected to flow of pedestrians.
\end{abstract}

Keywords - Pedestrian footbridges, Biodynamic models, Pedestrian-structure interaction, Human comfort.

\section{INTRODUCTION}

Steel and steel-concrete footbridges are more and more becoming the modern landmarks of urban areas. Designers seem to continuously move the safety border, in order to increase slenderness and lightness of their footbridges [1,2]. However, more and more pedestrian footbridges are carried out as light weight structures with low natural frequencies and low structural damping [1-9].On the other hand, the structural engineers experience and knowledge allied by the use newly developed materials and technologies have produced pedestrian footbridges with daring structures. These facts have generated very slender pedestrian footbridges, sensitive to dynamic excitation, and consequently changed the serviceability and ultimate limit states associated to their design. A direct consequence of this design trend is a considerable increase of excessive vibrations problems [1-9].Hence, the frequency of the actions associated to pedestrians (walking or running) may coincide with the fundamental frequency of the structure (resonance) and dynamic effects can't be neglected. It is also known that the dynamic response of the footbridges in resonance with the human-induced dynamic loads is considerably amplified when compared to the static response. Thus, these structures may vibrate excessively and cause discomfort to the pedestrians.In footbridges design, it is extremely important to conduct a dynamic investigation that takes into account the interaction of the pedestrian with the structure, so that a reliable result of the structure response can be obtained when subjected to large pedestrian loads. This analysis is justified mainly on structures with large spans or critical shapes that could suffer damage during use, with the risk of losing human lives and public resources.

The subject addressed in this paper has been studied by several researchers over the years. Bachmann [10] published the book "Vibration Problem in Structures: Practical Guidelines", which is used to be a reference to many researchers in the study of structural dynamics; Murray et al. [11] developed the design guide "Floor Vibrations due to Human Activity, Steel Design Guide Series" for the American Institute of Steel Construction (AISC), which brought important academic and practical contributions to researchers and structural designers in the area structural dynamics; the design guide SETRA [12] became one of the main international references for the verification of natural frequencies and peak accelerations of footbridges, proposing a practical analysis methodology for the evaluation of human comfort; finally, the design guide HIVOSS [13] established recommendations for the values of natural frequencies and maximum accelerations of pedestrian footbridges and also have proposed an analysis methodology determine the human comfort limits. In both design recommendations $[12,13]$, load classes are suggested for very low load situations in order to determine if the structure offers comfort in its use with regard to excessive vibration level for 
vertical, lateral and longitudinal vibrations. Debona [14] carried out a study on dynamic analysis, using the structural model of a footbridge located in a great circulation area in the city of Rio de Janeiro/RJ, Brazil, with a span of $82.5 \mathrm{~m}$. In addition, to evaluating the impact of the human heel and the spatial and temporal variation of the dynamic loading induced by the pedestrian, the author also compares the maximum peak accelerations values of the structure with the values established by design standards, considering the soil-structure interaction.

\section{HUMAN WALKING MODELLING}

In order to model the pedestrian-structure dynamic interaction, representative biodynamic models of people will be considered in this investigation. These models simulate conveniently the dynamic characteristics of the pedestrians (mass, stiffness and damping) and have been used as an efficient alternative to better evaluate the human comfort instead the traditional "hard force" model widely used for dynamic analysis of footbridges.

The biodynamic models can be described by a one degree of freedom (SDOF) or even multi degrees of freedom (MDOF). In the technical literature there are several proposals to represent the pedestrians in the vertical direction, like representing a person sitting or standing [15]-[17], for people jumping [18] or people running [19]-[20]. For people walking there are some recent proposals [21]-[25], with different aspects related to the number of degrees of freedom and the mass, damping and stiffness parameters used to simulate the pedestrians.

In this research work, the developed analysis methodology has considered that the pedestrians are modelled as "mass-spring-damper" systems, with a single degree of freedom (SDOF) [1,2]. These dynamic systems corresponding to the biodynamic models are coupled to the finite element model of the structural system (footbridge), in order to reproduce the pedestrian-structure dynamic interaction [1,2]. On the other hand, a dynamic force, $F_{p}(t)$, simulates the pedestrian crossing on the footbridge with a constant velocity $\mathrm{v}(\mathrm{t})$, see Figure 1 . The walking loading model implemented in this investigation can be represented based on the use of the biodynamic models in addition with a dynamic force produced by a combination of four harmonic forces with frequencies that are multiples or harmonics of the step frequency, $f_{s}$, for human walking.

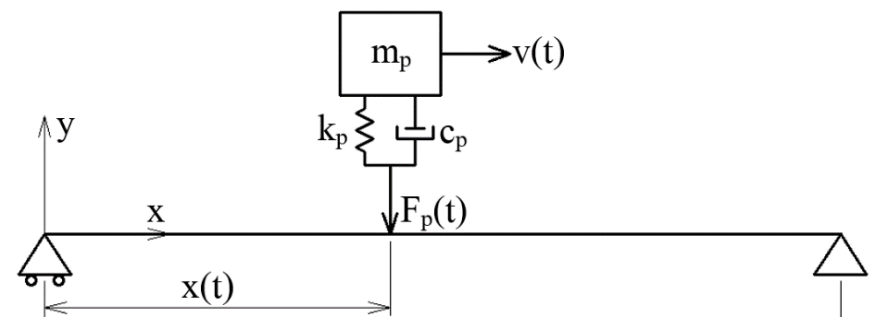

Figure.1Representation of the human walking on the footbridge.

The dynamic loading model has considered a space and temporal variation of the dynamic action on the structure and the time-dependent repeated force can be represented by the Equation (1). The harmonic forces appear due to interaction between the increasing load represented by a foot and the simultaneous unloading of the other foot. The mathematical representation of the vertical dynamic action induced by human walking is given by Equation (1).

$$
F(t)=P\left[\sum_{i=1}^{n} \alpha_{i} \cos \left(2 \pi i f_{p} t+\phi_{i}\right)\right]
$$

Where:

$\mathrm{F}_{\mathrm{p}}(\mathrm{t}) \quad$ : dynamic loading function;

$\mathrm{P} \quad$ : person's weight (800 N [1]);

$\alpha_{i} \quad$ : dynamic load factor;

i : multiple harmonic $(1,2,3$, etc. $)$;

$\mathrm{f}_{\mathrm{s}} \quad$ : step frequency; $\phi_{\mathrm{i}} \quad:$ phase angle for the harmonic i;

t : time.

However, it is necessary to incorporate other parameters in the walking representation, like step frequency, step distance and velocity. These variables are related to the excitation frequency values, dynamic coefficients and phase angles. In this work four harmonics were used to modelling the dynamic load. The values of the dynamic load factor and the phase angle were considered equal to: $\alpha_{1}=0.50 / \phi_{1}=0 ; \alpha_{2}=0.20 / \phi_{2}=\pi / 2 ; \alpha_{3}=0.10 / \phi_{3}=\pi / 2$ and $\alpha_{4}=0.05 / \phi_{4}=\pi / 2$ [10]. The parameters of the biodynamic models (pedestrians) were considered based on the experimental results described by Silva [24], with the value of mass $\left(\mathrm{m}_{\mathrm{p}}\right)$ equal to $68.58 \mathrm{~kg}$, damping $\left(\mathrm{c}_{\mathrm{p}}\right)$ of $841.56 \mathrm{Ns} / \mathrm{m}$, stiffness $\left(\mathrm{k}_{\mathrm{p}}\right)$ equal to $15085.56 \mathrm{~N} / \mathrm{m}$ and step frequency $\left(\mathrm{f}_{\mathrm{p}}\right)$ of $1.88 \mathrm{~Hz}$. 


\section{STRUCTURAL MODEL}

The investigated steel-concrete composite pedestrian footbridge is related to an existing structure, located in the city of Rio de Janeiro/RJ, Brazil, frequently used by students, cyclists, visitors and residents of the region in order to cross one of the most important avenues in the city, see Figure 2. The composite footbridge is composed of three simply supported spans, whose central span, object of this study, is $68.6 \mathrm{~m}$ long, divided into 28 symmetrical modules of $2.45 \mathrm{~m}$ each, height of 2.60 $\mathrm{m}$ and width of $2.55 \mathrm{~m}$, as illustrated in Figure 2 . The structure consists of steel profiles and precast concrete slabs, forming a steel-concrete composite system. The hollow profiles of rectangular shape are formed by steel plates welded at their ends. The structure also has a X-type bracing bars in the upper and lower plane of the modules, as presented in Figure 2.

\section{FINITE ELEMENT MODELLING}

The finite element modelling of the pedestrian footbridge adopted usual mesh refinement techniques present in the ANSYS program [26], see Figure 3. The numerical modelling of the system considered that both structural elements (steel sections and concrete slabs) have total interaction with an elastic behaviour.This way, for the numerical modelling of beams and columns and bars, the BEAM44 element was used, which allows the consideration of bending and torsion effects, while the concrete slab of the footbridge was modelled using the SHELL63 element and the bracing system of the model was simulated with element LINK8. The biodynamic models related to the pedestrians walking on the concrete slab of the footbridge were modelled based on the use of massspring-damping systems and represented by the use of two types of elements: MASS21 and COMBIN14. The biodynamic models representative of the pedestrians were modelled based on the use of single degree of freedom systems (SDOF), coupled to the nodes of the investigated footbridge finite element model and remain fixed along the dynamic analysis, when the simulation of pedestrians walking is considered, see Figure 4. The biodynamic models were uniformly distributed on the structure central span $(\mathrm{L}=68.6 \mathrm{~m})$, respecting a pedestrian spacing equal to $1 \mathrm{~m}$ for the most unfavourable loading situation and $1.47 \mathrm{~m}$ for the most favourable loading situation. Based on these hypotheses, it was possible to consider a maximum number of 140 pedestrians and a minimum of 46 pedestrians walking on the footbridge.

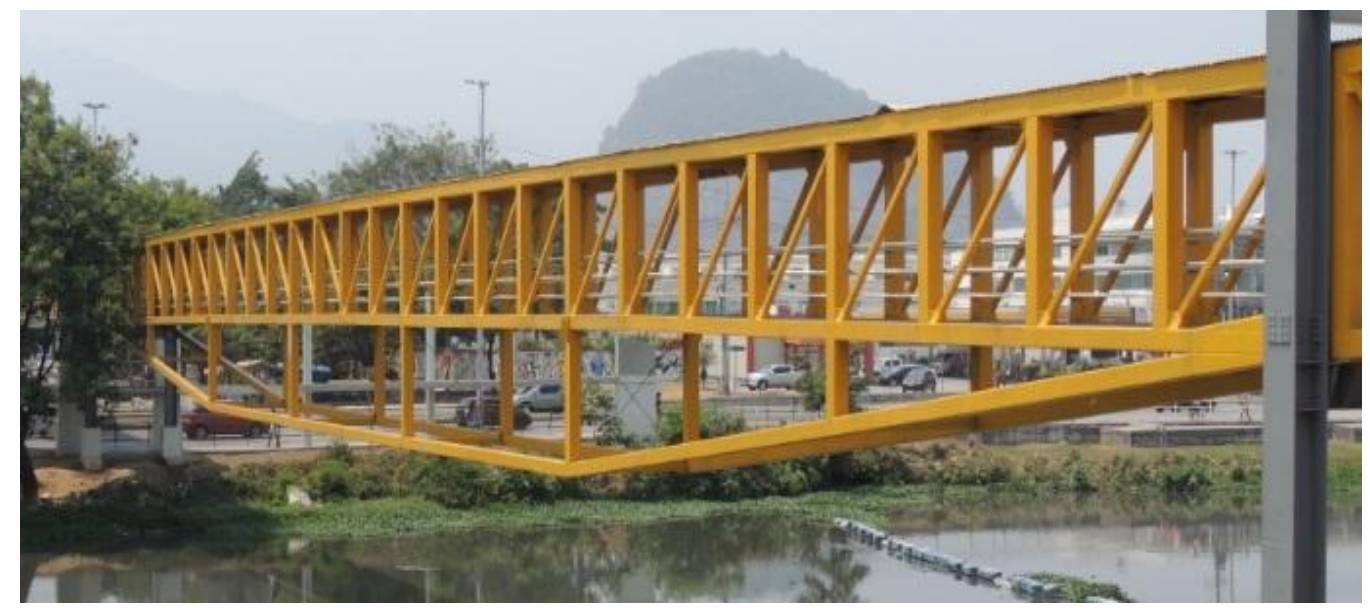

Figure2.Perspective view of the investigated pedestrian footbridge.

\section{DYNAMIC ANALYSIS}

The steel-concrete composite footbridge natural frequencies and peak accelerations values were determined considering the pedestrian-structure dynamic interaction, see Figure 4, with the aid of the numerical simulations, based on the finite element method using the ANSYS program [26].It must be emphasized that the first vibration mode presents a relevant modal mass and the associated natural frequency $\left[\mathrm{f}_{01}=1.94 \mathrm{~Hz}\right]$ is very close to the dynamic excitation related to the normal walking of the pedestrians, generating a possible resonance condition. Thus, the first vibration mode can be readily excited by the pedestrian dynamic action. Figure 5 presents the first footbridge flexural vibration mode and Table 1 shows the natural frequencies values of the structure considering the pedestrian-footbridge dynamic interaction. The dynamic analysis follows with the evaluation of the footbridge performance in terms of vibration serviceability due to dynamic forces induced by people walking. The first step is the determination of the peak accelerations values, based on a linear timedomain analysis. 


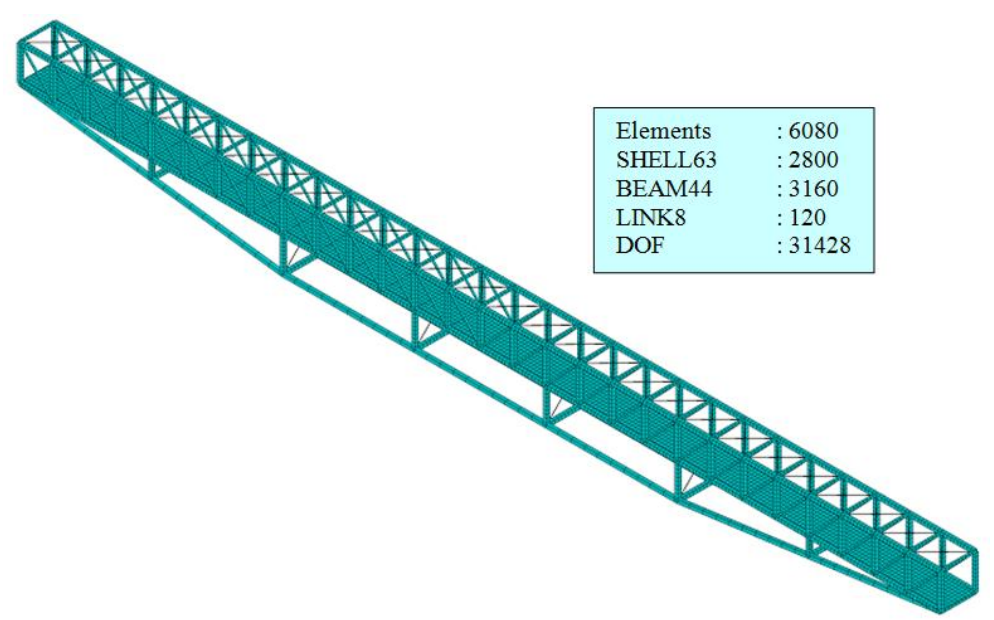

Figure3. Finite element model of the steel-concrete composite pedestrian footbridge.

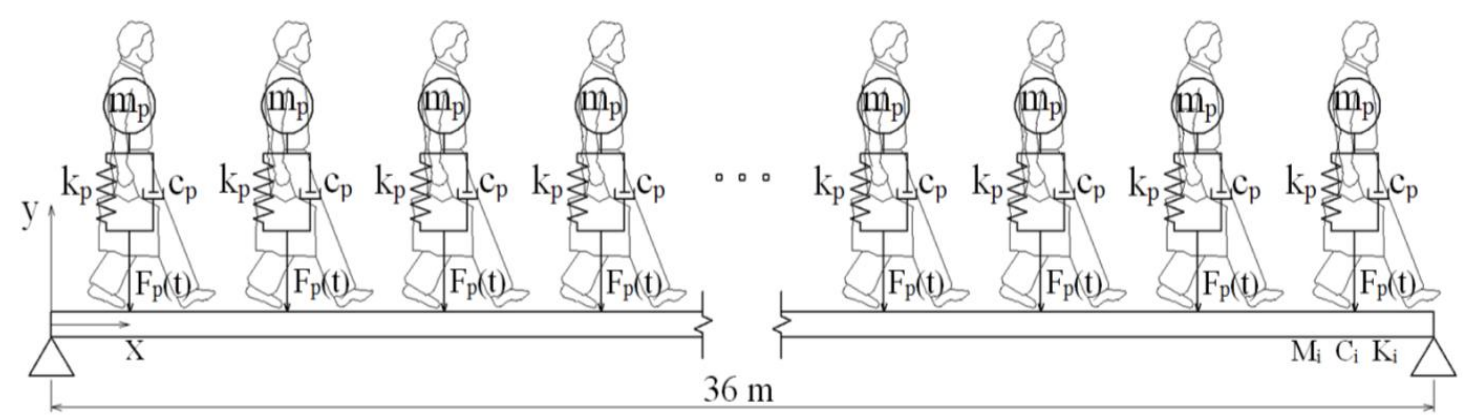

Figure4. Modelling of pedestrian-footbridge dynamic interaction.

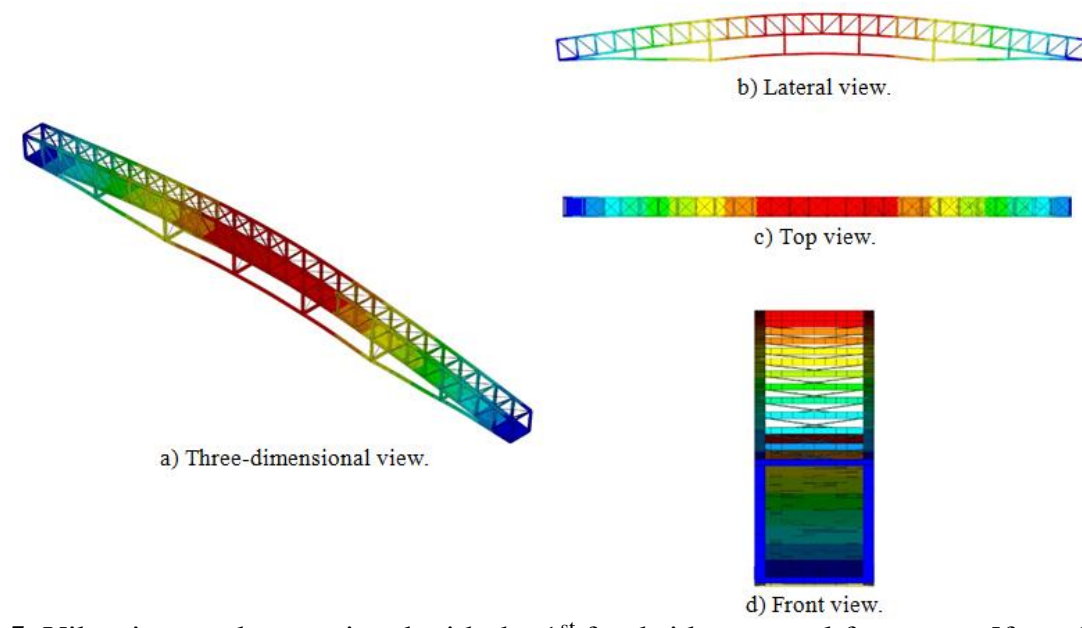

Figure 5. Vibration mode associated with the $1^{\text {st }}$ footbridge natural frequency $\left[f_{01}=1.94 \mathrm{~Hz}\right]$.

Table 1. Natural frequencies of the footbridge considering the pedestrian-structure dynamic interaction.

\begin{tabular}{|l|l|l|l|l|l|l|}
\hline \multirow{2}{*}{$\begin{array}{l}\text { Natural Frequencies } \\
(\mathrm{Hz})\end{array}$} & \multicolumn{7}{|l|}{ Number of Pedestrians on the Footbridge } \\
\cline { 2 - 7 } & 46 & 56 & 70 & 92 & 112 & 140 \\
\hline $\mathrm{f}_{01}$ & 1,83 & 1,83 & 1,82 & 1,78 & 1,77 & 1,73 \\
\hline $\mathrm{f}_{02}$ & 2,27 & 2,27 & 2,27 & 2,27 & 2,27 & 2,27 \\
\hline $\mathrm{f}_{03}$ & 2,34 & 2,34 & 2,33 & 2,33 & 2,32 & 2,31 \\
\hline $\mathrm{f}_{04}$ & 4,71 & 4,72 & 4,73 & 4,74 & 4,75 & 4,78 \\
\hline $\mathrm{f}_{05}$ & 5,62 & 5,62 & 5,63 & 5,63 & 5,63 & 5,63 \\
\hline $\mathrm{f}_{06}$ & 6,79 & 6,79 & 6,79 & 6,79 & 6,79 & 6,79 \\
\hline
\end{tabular}


The Table 1 results show a reduction of the fundamental frequency value of the footbridge. The reduction of the fundamental frequency of the structure is explained in part by the significant increase in the modal mass of the structure with the increase in the number of pedestrians, as shown in Table 1. It can be seen that the change in the natural frequencies is more noticeable for the first vibration mode (flexural mode), while for the other vibration modes the frequency change is less significant. In the dynamic analysis (forced vibration), the change in natural frequencies of the structure based on the use of biodynamic models (pedestrian-structure interaction), and the dynamic loadings related to the pedestrians walking are studied. Considering the study of the vertical peak accelerations resulting from the application of the dynamic excitations, a comparison between the values calculated using the methodologies provided by international design guides such as SETRA [3] and HIVOSS [4] is analysed and the human comfort of the footbridge is evaluated. In one-row dynamic loading situations, the pedestrians walking were arranged on the middle of the footbridge concrete slabs, providing symmetry when 46, 56 and 70 pedestrians are considered in the analysis. On the other hand, for the remaining dynamic loading situations, two rows with the same number of pedestrians were adopted $(92,112$ and 140 pedestrians).The dynamic analyses were performed considering pedestrians step frequencies values between $1.7 \mathrm{~Hz}$ and $2.3 \mathrm{~Hz}$, in order to study the structure when it presents a behaviour close to the resonance, for the two different modelling approaches developed in this work: "traditional hard force" and based on the use of biodynamic models (pedestrian-footbridge dynamic interaction). This way, in sequence of the investigation, Figure 6 illustrates the general dynamic behaviour of the peak accelerations, in time domain, at the central section (central span) of the studied footbridge, when 70 pedestrians walk on the structure (normal walking).

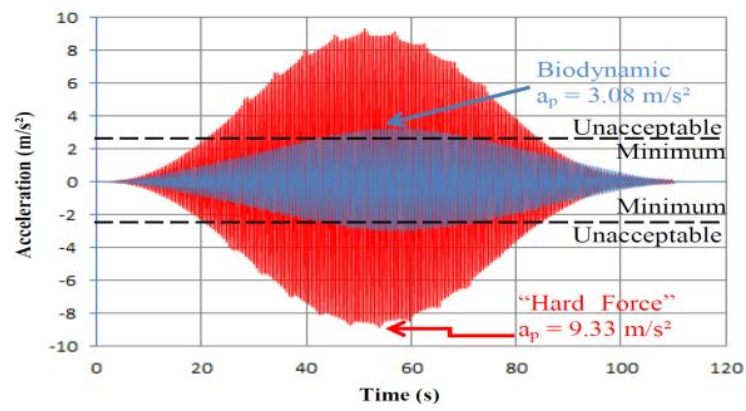

Figure 6.Vertical acceleration, in time domain, produced by 70 pedestrians walking on the concrete slabs with step frequency $\left[f_{p}=1.80 \mathrm{~Hz}\right]$ close to the fundamental frequency of the footbridge $\left[\mathrm{f}_{01}=1.82 \mathrm{~Hz}\right]$.

Comparing the two developed modelling approaches ["hard force" model and biodynamic model], it was observed that the highest peak acceleration values near the resonance occur in the "hard force" model, as illustrated in Figure 6.Considering the loading situation with 70 pedestrians walking (regular walking) on the concrete slab of the footbridge, the peak acceleration value found using the "hard force" model was equal to $9.33 \mathrm{~m} / \mathrm{s}^{2}\left(a_{\mathrm{p}}=9.33 \mathrm{~m} / \mathrm{s}^{2}\right)$, which correspond approximately three times higher than the one found when the biodynamic model was considered in the analysis $\left(a_{p}=3.08 \mathrm{~m} / \mathrm{s}^{2}\right)$, see Figure 6 . This fact is very relevant and can be explained due to the damping and stiffness characteristics included in the biodynamic systems, used to represent the pedestrians (see Figures 1 and 4), which are added to the dynamic properties of the structural model. In sequence, Table 3 presents the values of the peak accelerations obtained using the simplified design recommendations prescribed in the main international guides currently used for the human comfort analysis of pedestrian footbridges (SETRA [3] and HIVOSS [4]).

Table 3. Comparison between the peak accelerations values obtained by design guides and the present study.

\begin{tabular}{|l|l|l|}
\hline $\begin{array}{l}\text { Number of Pedestrians } \\
\text { Walking on the } \\
\text { Footbridge }\end{array}$ & $\begin{array}{l}\text { Design Guides } \\
\text { SETRA [3] and HIVOSS [4] } \\
\mathrm{a}_{\mathrm{p}}\left(\mathrm{m} / \mathrm{s}^{2}\right)\end{array}$ & $\begin{array}{l}\text { Pedestrian-Structure Dynamic } \\
\text { Interaction (Biodynamic Model) } \\
\mathrm{a}_{\mathrm{p}}\left(\mathrm{m} / \mathrm{s}^{2}\right)\end{array}$ \\
\hline 46 & 2.20 & 1.86 \\
\hline 56 & 2.41 & 2.03 \\
\hline 70 & 2.66 & 2.24 \\
\hline 92 & 2.99 & 2.57 \\
\hline 112 & 3.24 & 2.83 \\
\hline 140 & 3.53 & 2.96 \\
\hline
\end{tabular}


Considering the results presented in Table 3 , it can be concluded that the peak accelerations values $\left(a_{p}\right)$ obtained through the international design guides SETRA [3] and HIVOSS [4] are of the same order of magnitude as those obtained through the dynamic analysis using the biodynamic models. However, it must be emphasized that these guides consider a single degree of freedom (S1GL) formulation and do not include the dynamic characteristics of the pedestrians. On the other hand, the same order of magnitude of the dynamic structural response (peak accelerations) obtained based on very different approaches shows the consistency of the results determined from the use of the developed analysis methodology in this investigation (biodynamic modelling), when compared with simplified formulas.

\section{CONCLUSIONS}

Throughout the analyses, it was observed that the fundamental frequency value of the investigated steel-concrete composite footbridge [ $\mathrm{f}_{01}$ $=1.94 \mathrm{~Hz}$ : without pedestrians] is in a complex range of natural frequencies very close to the dynamic excitation frequencies originated by pedestrian walking. This fact explains the high level of discomfort experienced by users of this particular footbridge, since the fundamental frequency value of the model is very close to the pedestrian step frequency, for example for a normal walking $\left(\mathrm{f}_{01}=\right.$ $1,94 \mathrm{~Hz}$ and $f_{p}=2.0 \mathrm{~Hz}$ ). The coupling of the biodynamic models to the finite element model influenced significantly the dynamic structural response, especially with respect to the change in the fundamental frequency of the footbridge, causing an important reduction in its value. For example, considering the loading situation related to 140 pedestrians walking on the structural model, the fundamental frequency value of the footbridge was reduced from $1.94 \mathrm{~Hz}$ to $1.73 \mathrm{~Hz}$, which is very close to pedestrian step frequency for a slow walk $\left(f_{p}=\right.$ 1.70 Hz). The highest values for peak accelerations at design situations close to resonance usually occur when the "hard force" model is used. However, the importance of the numerical comparison performed during each investigated loading situation this research work is emphasized, since the adjustment of the natural frequencies of the footbridge in relation to the pedestrian step frequency is very relevant and may lead to a false interpretation of the results.

On the other hand, in general, these acceleration values tend to be smaller when the biodynamic model (pedestrian dynamic-structure interaction) are considered in the analysis, since in this situation the inertial and damping effects contribute favourably to attenuate the dynamic structural response of the footbridge. It should also be noted that the methodology that uses the "hard force" mathematical formulation (simplified model), tends to provide very high acceleration values, usually outside the practical reality of design.It is also worth noting that the biodynamic numerical models need to be further investigated and it is necessary to carry out an extensive parametric study, taking into account the possibility of using more degrees of freedom in these models, as well as change in the dynamic properties (mass, stiffness and damping). Considering the dynamic excitation related to the human walking investigated in this research work and also the variation of the number of pedestrians considered in the studied loading cases (46 to 140 pedestrians), it was possible to verify that the peak accelerations values were quite high, especially with respect to the resonance situation in the investigated footbridge. It must be emphasized that the value of the structural model fundamental frequency, as well as the proximity of this value to the pedestrian step frequency (human walking), in numerous design situations, led to values of peak accelerations that surpassed the limiting values established in international design guides and recommendations. This fact leads the footbridge to excessive vibrations and human discomfort.

\section{ACKNOWLEDGEMENTS}

The authors of this research thank the financial support provided by the country's Research Promotion Agencies: CAPES, CNPq and FAPERJ.

\section{REFERENCES}

[1] I.F.B. Duarte, Human Walking Modelling and Human Comfort Analysis of Pedestrian Footbridges Based on Biodynamic Models. MSc. Dissertation (In Portuguese). Civil Engineering Post-graduate Programme, PGECIV. State University of Rio de Janeiro, UERJ. Rio de Janeiro/RJ, Brazil, 2016.

[2] G.L. Debona, Experimental Monitoring and Numerical Modelling on the Dynamic Structural Response of Pedestrian Footbridges. PhD Thesis (In Portuguese). Civil Engineering Post-graduate Programme, PGECIV. State University of Rio de Janeiro, UERJ. Rio de Janeiro/RJ, Brazil, 2016.

[3] J.M.W. Brownjohn and T.N. Fu, Vibration excitation and control of a pedestrian walkway by individuals and crowds. Shock and Vibration, 12, 333-347, 2005.

[4] H. Fernandes, Dynamic Behaviour of Footbridges Modelled as Beams Subjected to Vertical Vibrations Induced by Pedestrians. PhD Thesis (In Portuguese). Federal University of Paraíba. Mechanical Engineering Post-graduate Programme, 
PPGEM/UFPB, João Pessoa, Paraíba, Brazil, 2007

[5] C. Butz, M. Feldmann, C. Heinemeyer, G. Sedlacek, B. Chabrolin, Lemaire A. , M Lukic, P.O. Martin, E. Caetano, A;. Cunha, A. Goldack, A. Keil, M. Schlaich, Advanced load models for synchronous pedestrian excitation and optimised design guidelines for steel footbridges. European Commission, pp. $167,2008$.

[6] C. Barker, D. Mackenzie, Calibration of the UK National Annex. Proceedings of the International Conference Footbridge 2008: Footbridges for Urban Renewal, Porto, Portugal, 2008.

[7] Venuti F., Racic V., Corbetta A., Pedestrianstructure interaction in the vertical direction: coupled oscillator-force model for vibration serviceability assessment. Proceedings of the 9th International Conference on Structural Dynamics, EURODYN 2014, 915-920, 2014.

[8] M.S. Pfeil, N.P.A. Costa, R.L. Pimentel, R.P. Vasconcelos, Analytic-numerical model for walking person - footbridge structure interaction. Proceedings of the 9th International Conference on Structural Dynamics, EURODYN 2014, 1079-1085, 2014.

[9] J.F.J. Alonso, A. Saez, E. Caetano, A. Cunha, Proposal and calibration of an humanstructure interaction biomechanical model by the resolution of the inverse dynamic problem. Proceedings of the 9th International Conference on Structural Dynamics, EURODYN 2014, 975-982, 2014.

[10] H. Bachmann, W.J. Ammann, F. Deischl, J. Eisenmann, J. Floegl, G.H. Hirsch et al., Vibration Problems in Structures - Practical Guidelines, Basel (Switzerland):Institut für Baustatik und Konstruktion, Birkhäuser, 1995

[11] T.M. Murray, D.E. Allen and E.E. Ungar, Floor vibrations due to human activity (Steel Design Guide Series, American Institute of Steel Construction, AISC, Chicago, USA, 2003

[12] SÉTRA Footbridge, Assessment of Vibrational Behaviour of Footbridge Under Pedestrian Loading (Technical guide. Service d'Etudes Techniques des Routes et Autoroutes, Paris, France, 2006.

[13] HIVOSS (Human Induced Vibration of Steel Structures), Design of Footbridges Guideline (Research Fund for Coal and Steel, 2008.

[14] G.L. Debona, Modelling of the Dynamic Behaviour of Steel and Steel-Concrete Tubular Footbridges. MSc. Dissertation (In Portuguese). Civil Engineering Post-graduate
Programme, PGECIV. State University of Rio de Janeiro, UERJ. Rio de Janeiro/RJ, Brazil, 2011.

[15] ISO 5982, International Organization for Standardization. Bases for Design of Structures - Vibration and Shock-Mechanical driving point impedance of the human body, 1981.

[16] Y. Matsumoto, M.J. Griffin, Mathematical models for the apparent masses of standing subjects exposed to vertical whole-body vibration, Journal of Sound and Vibration, 260, 431-451, 2003.

[17] R. Sachse, A. Pavic, P. Reynolds, Humanstructure dynamic interaction in civil engineering dynamics: a literature review. The Shock and Vibration Digest, 35 (1), pp. 3-18, 2003.

[18] A. Nhleko, A. Zingoni, P. Moyo, A variable mass model for describing load impulses due to periodic jumping. Engineering Structures, 30, 1760-1769, 2008

[19] D.P. Ferris, M. Louie, C.T. Farley, Running in the real world: adjusting leg stiffness for different surfaces". Proc. R. Soc. London, B265, pp. 989-994, 1998.

[20] B.B. Nigg, W. Liu, The effect of muscle stiffness and damping on simulated impact force peaks during running. Journal of Biomechanics, 32, pp. 849-856, 1999.

[21] Y. Miyamori, T. Obata, T. Hayashikawa, K. Sato, Study on identification of human walking model based on dynamic response characteristics of pedestrian bridges. The Eighth East Asia-Pacific Conference on Structural Engineering and Construction, CDROM, Paper N0 1066, 2001.

[22] SH. Kim, K.I. Cho, M.S. Choi, J.Y. Lim, Development of human body model for the dynamic analysis of footbridges under pedestrian induced excitation. Steel Structures, 8, 333-345, 2008.

[23] C.C. Caprani, J. Keogh, P. Archbold, P. Fanning, Characteristic vertical response of a footbridge due to crowd loading, Proceedings of the 8th International Conference on Structural Dynamics, EURODYN 2011, Leuven, Belgium, 2011.

[24] F.T. Silva, Vibration of Pedestrian Footbridges in Vertical Direction Considering Biodynamic Models of People Walking (In Portuguese), $\mathrm{PhD}$ Thesis (In Portuguese). Federal University of Paraíba. Mechanical Engineering Post-graduate Programme, PPGEM/UFPB, João Pessoa, Paraíba, Brazil, 2011.

[25] N.P.A. Costa, Effect of the Dynamic Interaction Person-Structure on Composite 
Footbridges. MSc Dissertation. Federal University of Amazonas. Civil Engineering Post-graduate Programme, PPGEC/UFAM, Amazonas, Brazil, 2013.

[26] ANSYS, Swanson Analysis Systems, Inc., P.O. Box 65, Johnson Road, Houston, PA, 15342-0065, Version 10.0, Basic analysis procedures, Second edition, 2009. 